CESIS Electronic Working Paper Series

Paper No. 167

\title{
New Firm Formation and Economic Development in a Globalizing Economy
}

\author{
Sierdjan Koster and Charlie Karlsson \\ $\left({ }^{*} \mathrm{CESIS}\right.$ and JIBS, ${ }^{* *}$ George Mason University)
}

January 2009 


\title{
New firm formation and economic development
}

\section{in a globalizing economy}

\author{
Sierdjan Koster* and Charlie Karlsson ${ }^{\dagger}$
}

\begin{abstract}
This paper provides an overview of how globalization can impact on new firm formation and its consequence on regional economic development. Although there is a large body of research on new firm formation, the economic context in which new firm formation takes place has received considerably less attention. Globalization, changes conditions for new firm formation and it may change the role of new firm formation in economic development. The main conclusion of this review is that there is very little concrete understanding about if and how globalization actually impacts on new firm formation. Thus, the conclusion of this paper is probably best read as suggestions for research that addresses the issue of new firm formation in a globalizing economy. We distinguish two main avenues for research. The first avenue is on the firm level and is concerned with the issue to what extent new firms are actually influenced by globalization. The second avenue is on the regional level and addresses the question if and how globalization will impact on the regional distribution of new firm formation. Although globalization may open up the world market for many regions, it is uncertain whether this will lead to a reshuffle of economic development, for example governed by developments in new firm formation. Competition is fierce and it is a question of which regions are ready to take the opportunities that globalization offers.
\end{abstract}

Keywords: New Firm Formation; Economic Development; Regional Development; Globalizing Economy, Innovation, Productivity Growth, Employment Growth

JEL Classification: M13; O10; L10; R11

\footnotetext{
* Urban and Regional Studies Institute, Groningen University and Jönköping International Business School

${ }^{\dagger}$ Jönköping International Business School, Centre of Excellence for Science and Innovation Studies
} 


\section{New firm formation in a globalizing economy}

Entrepreneurship is an important driver of economic development (See, for example, Baumol, 1968). The positive relationship between entrepreneurship, often conceptualised as new firm formation, and economic development has been shown in several ways both theoretically and empirically. Arguably, the most influential explanation is given by Schumpeter (1912) who described the rejuvenating role of entrepreneurship. New firms challenge existing firms, forcing incumbents to constantly improve their products and production techniques. Firms that cannot live up to the challenges set will eventually disappear. As a result, the fittest firms remain, governing economic growth.

The expected positive relationship between new firm formation and regional economic development has inspired many empirical studies. The result is a considerable body of research that shows a piecemeal advancement in our understanding of the role of new firm formation in regional economic development: many variables have been added to improve the empirical fit of the models, many case-studies have been conducted to extend the arguments used. The special issues in Regional Studies $(1984,1994,2004)$ devoted to this topic provide insightful overviews of the headway that is made over the last decades (Acs and Storey, 2004). And indeed, most studies do find the expected positive relationship (Fritsch and Mueller, 2004).

Although there is a large research body on new firm formation and regional economic growth, little is known about the context of this relationship. In other words, the question whether the characteristics of new firm formation change over time and how this affects its role in economic development is rarely asked. A priori, a positive relationship between new firm formation and economic growth is normally expected. There are indications, however, that the link between new firm formation and economic development is not necessarily stable over time or space. Baumol (1990), for example, points out the possible destructive nature of some types of entrepreneurship, causing economic growth to slow down. Another telling example is the period after the Second World War in which economic development was regarded as the result of increasing scale economies. This was realised most efficiently in large companies, Ford being the archetype organization in this respect. The resulting high entry barriers precluded any important role of new firm formation. Both examples show that the role of new firm formation in economic development may change over time depending on the context ${ }^{1}$ in which new firm formation takes place. Only after the seminal work by Birch (1979), who recognised the importance of small firm formation in employment generation, did new firm formation become a relevant topic for both researchers and policy makers. It shows that the impact of new firm formation is nor natural or automatic and may change in the face of a system shift.

\footnotetext{
${ }^{1}$ In addition to the high entry barriers to entry, new firm formation was also discouraged because institutions were installed in support of large companies. Labour unions, governments and other actors were framed within the context of large scale companies, creating an institutional barrier for small firms in addition to the high barriers to entry emanated from the importance of scale economies.
} 
Arguably, the ongoing globalization of the world economy entails one such system shift. Following Dicken's definition (2007), globalization describes the road towards a qualitatively different world economy with internationalisation of economic activities as one of its core elements. The question raised in this chapter pertains to the role and characteristics of new firm formation in the context of a globalizing world. Does a qualitatively new economic context change the role new firm formation plays in the development of national and regional economies? In order to answer this question, the chapter reviews existing evidence concerning the relationship between new firm formation and economic development in the light of globalization.

\subsection{Globalization and its driving forces}

This chapter does not aim at contributing to the discussion about the highly contested notion of globalization. It takes the changing economic environment, captured under the embracing name of globalization, as a given and develops the argument concerning new firm formation from there. We distinguish two main drivers of globalization: increased possibilities for communication and transportation on the one hand and institutional integration and deregulation on the other (Reynolds, 1997). This is, of course, a narrow definition that disregards any cultural, political or sociological meanings of globalization. It does, however, provide a workable economic conceptualisation that can be translated into concrete economic developments that pertain to new firm formation. We distinguish three such aspects: increased spatial market size, the emergence of new industries and increased speed which leads to shorter product life cycles.

Technological progress in communications and transport as well as institutional integration and deregulation of trade work towards an increasing market size for products and production factors, including knowledge, capital and human capital. Technological progress has caused a decrease of travel and transportation costs. Not only costs as such have decreased, also improved reliability and availability (think of increased bandwidth of internet connections) have led to an overall lower level of transportation and communication costs. With this, there is a tendency for total transaction costs to decrease. As transaction costs partly determine the spatial boundaries of markets (see, for example, Christaller, 1933), a decline in transaction costs can be translated into an increase of spatial markets. Similarly, political and institutional integration are aimed at decreasing that part of transaction costs that is the result of institutional differences between countries. The common market of the EU in which labour, capital, products and services can flow freely is probably the most telling example in this respect, but also organizations such as WTO, Worldbank, Mercosur, NAFTA, AFTA work towards this end.

A second and closely related aspect is the emergence of new industries, or at least a shift towards other industries, notably service industries. Beyers (2002) summarizes this as the emergence of the 'new economy'. There are two elements at play here. Firstly, the emergence of new communication and transportation technologies has created a new industry in itself. Secondly, 
digitalization has increased the number of tradable goods (Friedman, 2005). Friedman gives the example of x-ray images that are digitalised and sent to India for assessment. This development particularly affects those industries that work with information that can be digitalised, enabling worldwide distribution.

Thirdly, increased possibilities for rapid communication and transportation have led to an increased speed of knowledge dissemination. As markets grow, product characteristics are known quickly to many consumers and competing producers. This makes the propensity of imitation and further development greater. This, in turn, results in shorter periods of competitive advantage for the producing firm. Competition may be imminent as product-related knowledge becomes available to an increasing pool of entrepreneurs. As a result, the product-life cycle of products, particularly the ones that can be distributed easily, tends to decline. The increased speed forces companies to be flexible in the production and marketing of products. Flexibility is guaranteed by globally sourcing supplies for production in a just-in-time delivery system, forcing suppliers to be equally flexible. In order to manage the global supply chain communication technology plays a pivotal enabling role.

In sum, we take globalization as the process that increases the spatial market size of production and production factors. In addition, it shows a tendency towards service industries and an increase in the speed of market and product development, which tends to decrease the product lifecycle. We do not go into the globalization debate that in essence asks whether to what extent these forces play a role. Indeed, communication costs are still important and there are still important institutional and cultural differences between countries (Hofstede, 2001). In addition, in many cases deregulation is actually reregulation (Dicken, 2007). And indeed, not all products can be distributed globally. However, for the argument of this paper we use these tendencies and argue how they could influence new firm formation and its impact on regional economic development. This makes clear the questions that can be asked in assessing the issue of new firm formation in a globalized world.

\subsection{Outline}

The remainder of the paper has been divided into two parts. First, in Section 2, the framework for explaining regional differences in firm formation is assessed. Section 3 then continues by addressing the question how the relationship between new firm formation and regional economic development may develop in the face of globalization. Section 4 concludes.

\section{Drivers of New Firm Formation}

In the explanation of new firm formation, two main perspectives can be distinguished. The first perspective is at the individual level and is part of labour market economics. In this approach, new firm formation is a problem of occupational choice in which a person decides between wage employment, self-employment and unemployment. This decision can be thought of as a trade-off between expected incomes and costs of the new firm and expected incomes and costs of the other 
options. If the overall expected profit ${ }^{2}$ exceeds the expected income from either employment or unemployment, an individual is inclined to become self-employed. Because both costs and income are uncertain, also the risk that an individual is willing to take influences this decision (Knight, 1921). The decision of becoming self-employed is thus dependent on the expected costs and incomes and the risk level that an individual is willing to accept. Trait studies have tried to capture risk acceptance in personal characteristics of entrepreneurs (see for an early overview, Chell, 1986). The second perspective on new firm formation takes a macro perspective and regards regional differences in new firm formation. Although two distinct perspectives, it is clear that the individual and the regional level are closely linked. Firstly, regional differences in new firm formation are the result of accumulated decisions by individuals. Secondly, individual decisions are influenced by aspects, such as an entrepreneurial culture, that are at an aggregate level. Verheul et al. (2001) give an overview of both strands of research. At the regional level, they distinguish between demand factors and supply factors that influence upon regional new firm formation. The interaction between demand and supply takes place within the regional framework that is formed by the culture and institutions in place. This general context in which economic decisions are made has also been referred to as the regional economic milieu (Karlsson, 2001). The following sections are ordered according to the distinction between demand, supply and economic context. For each of these aspects, the possible impact of globalization is described.

\subsection{Supply side: production factors and human capital}

The link between the individual and the regional level is probably most apparent at the supply side. The number and quality of people that are willing to start new firms ultimately determine regional new firm formation. It will not only determine the number of new firms, it will also influence the types and quality of the foundings which in turn influences economic development. Fritsch and Mueller (2007) argue that supply side dynamics are the most important explanation for changes in the level of new firm formation. They find that knowledge, generating innovations to base new firms on, and unemployment, forcing people into self-employment, are the most important explanatory variables for changes in new firm formation rates. These findings tie in with two important supply factors of regional firm formation; human capital and knowledge and resources for production.

The supply side of new firm formation is inherently local. Most founders do not go through extensive searches for the optimum location and start their firms in the immediate surroundings of their place of residence, very often even at home (Klepper, 2001). It is only in later stages of the firm life-cycle, and only when relevant, that business owners search more extensively for other locations (Stam, 2003). Despite its local character, the supply side of new firm formation may be

\footnotetext{
${ }^{2}$ The same argument can be made using the concept of utility.
} 
importantly influence by globalization. The characteristics of the local supply pool, notably the available knowledge, may change.

Firstly, international migration may influence the regional supply of founders. Particularly in larger cities migrant or ethnic entrepreneurship has increased quickly over the last years. There are several reasons for the increased level of self-employment in this group. Migrants may come from cultures in which entrepreneurship is common. Migration brings in people with an entrepreneurial mindset which can enhance regional new firm formation. This effect is strengthened by the effect that the most entrepreneurial people are also more inclined to migrate. In addition, lower educational attainment in combination with increased levels of unemployment may induce necessity entrepreneurship. The last two factors suggest that origin, as an indicator of entrepreneurial culture, is not important as such, but rather the context of the receiving region and the personal characteristics of migrants. Indeed, Levie (2007) finds, after correcting for other variables, only a small residual effect of being a foreign immigrant in the explanation of start-up propensity. The same effect is found for non-foreign migrants, suggesting that the local context is most important in determining entrepreneurial behaviour by migrants. This idea is further evidenced by his finding that there are regional differences in the propensity of migrant workers to become self-employed. In a similar vein, Baycan-Levent and Nijkamp (2005) show large differences in the entrepreneurial activities of foreign migrants across Europe. Both studies show that, although migrants may influence the local supply of entrepreneurs, local conditions remain very important in determining entrepreneurial activities by migrants.

Secondly, the presence of international firms can influence local supply. Given the fact that most new firms are started by persons who were previously employed (Garvin, 1983 and Acs et al., 2006), a large share of FDI in a regional economy may influence the nature of new firm formation efforts. The availability of specific product knowledge may induce employees to imitate or complement the product. Shane $(2000,2005)$ shows that business opportunities conceived by entrepreneurs are influenced by their previous positions. Knowing the relevant actors in a field and having relevant information enhances the probability of identifying a profitable business opportunity. Koster (2006) shows that most relevant knowledge from previous employment pertains to products and production methods. If a large share of local employment is in internationally active firms, this will impact on the type of knowledge available to the employees. In addition, foreign firms may spill knowledge through local input and output relations. Indeed, there is empirical evidence for Ireland that FDI has led to increased levels of entrepreneurship in the same sectors and downstream in the value chain (Acs et al., 2007a; Görg and Strobl, 2002). In addition, entrepreneurs in open economies, in terms of trade shares and FDI investments, are more likely to engage in international activities themselves (De Clercq et al, 2007). This suggests that local entrepreneurs capitalize on knowledge spill-overs originating from multinational firms. 
The relevant question is which regions will experience these effects and which regions will remain rather unaffected. Inflows from both migrants and foreign firms have distinct regional patterns with a clear focus on larger urban areas (see, for example, Barrell and Pain, 1999). The supply side effects of globalization are likely to be prominent particularly in those areas. Not only the location of migrants and FDI influences the overall effect, also the characteristics of the local labour market force are important. FDI may form a new source of knowledge and resources that would otherwise be unattainable for a region. However, in order to make use of this a labour market population that has the ability to tap into these resources is pivotal. High education and a good understanding of foreign languages seem to be important for this. Again urban areas have the upper hand on these characteristics.

\subsection{Demand side: going global}

The rapid development of communication and transportation technology has decreased transportation costs considerably (Dicken, 2007). Particularly products and services that can be digitalized can be transported over great distances at virtually no marginal costs. The spatial boundaries of many product markets have been stretched as a result. Not only are markets growing in size, the characteristics of local markets are also affected by globalizing forces. This section explores both aspects.

The increasing spatial size of markets has a twofold effect on regional firm formation. In one sense it levels the playing field because location, from a demand perspective, is less important in a global market. This opens up possibilities for entrepreneurs in peripheral locations with relatively small home markets. In terms of the individual decision model, the expected income of selfemployment increases because potential demand increases. Particularly regions with small home markets can benefit from this as the relative increase of potential demand is greatest in these areas. This is illustrated by the inflow of entrepreneurs from new EU member states, such as Poland and Czech Republic, into countries such as the Netherlands, the UK and Germany. There are two arguments, however, that work against the possibilities that an increased market size may offer. As a result, it is unclear whether an increasing market size involves increased possibilities for entrepreneurs with small home markets.

Firstly, market access is not only increasing for entrepreneurs from small home markets. Entrepreneurs from stronger markets may enter increasing competition in the process. Firms are no longer only competing with other local suppliers, firms from all over the globe may prove competitors. The current inflow of Polish construction firms in countries such as Germany, the Netherlands, the UK and Sweden, shows that this effect does not only apply to sectors in which products can be digitalised. Through competition, local excellence may become crucial, which induces regional clustering of activities. This may decrease the opportunities for entrepreneurs from small home markets. 
Secondly, it is questionable whether new firms actually have the means of accessing the increasing market. Do new firms actually serve global markets right after start-up? The answer to this question is unclear still. Reynolds (1997) answers in the affirmative as he conjectures, based on an OECD study, that in $200580 \%$ of all SMEs (firms with less than 100 employees) are involved in or affected by international trade, although he does not go into details about how this figure was constructed. Likewise, McDougall and Oviatt (2000) stress the impact of 'born globals', new firms that are immediately active on international markets. Other studies show more nuanced views. For the UK, Westhead et al (2001) find only $25 \%$ of all firms to be exporters of which only $6 \%$ (in 1991) and $10 \%$ (in 1997) reported over $15 \%$ of total sales to be international. Recent figures come from the 2006 GEM report (Suddle and Hessels, 2007). The European average of new firms (3 years and younger) with more than $25 \%$ international sales was $20 \%$. This amounts to $1-5 \%$ of total export generated by new firms. In comparison to Swedish data this is still a large share. Andersson (2007) finds the share of exporting firms to be around 5\%, with most of these firms exporting to only one country. In conclusion, it seems fair to say that the bulk of new firms still aim at non-international regional markets. It is, however, difficult to give an overall picture or trend on this issue. The distinct operationalisation of variables and data differences prevent any solid comparison between the studies.

Although, on average, market size may be increasing, this does not necessarily lead to convergence of new firm formation possibilities, because at the same time competition between firms intensifies stimulating divergence. In addition, new firms are still mostly active in regional markets raising the question to which extent an increasing market size is actually relevant for new firms. Still, the impact of market developments on new firm formation is a relevant issue. If demand is global rather than local, it may be appropriate to include global demand variables, in addition to local demand variables (see, for example, Verheul et al., 2001 and Reynolds et al, 1995), in estimations of regional firm formation rates. Firms can, however, also be affected by globalization while remaining active in local and national markets.

Particularly when FDI firms engage in local supplier relationships, the impact on local demand can be considerable. Florida (1996) and Acs et al (2007a) show how FDI has had a decisive impact on regional economic developments in the Midwest of the USA, in Ireland and in Hungary. In these regions, FDI has importantly governed demand and the possibilities for new firm formation, both in quantitative and qualitative terms. Although recent studies tend to stress the positive effects of FDI, the debate about the impact of foreign subsidiaries was ignited by negative sentiments regarding the inflow on foreign subsidiaries to the UK; subsidiaries were expected to offer only low-quality employment that can be retracted easily when the economic tide becomes less favourable (Townroe, 1975). Perhaps a legitimate concern when FDI was mainly based on cheap-labour arguments, it seems less applicable now because FDI seems to be mainly a tool of accessing strategic high-quality assets (Acs et al, 2007b). This requires long-term relations with local actors, embedding the foreign firm in a local economy. The shift also shows that FDI will be particularly located in those regions that have a -9 - 
competitive edge over other regions in terms of the availability of human capital and other strategic assets. In that sense the shift seems to be biased towards the developed world. In cheap labour economies FDI may still be volatile, retracted at the moment another place becomes more attractive.

\subsection{Institutions and new firm formation: Deregulation and culture}

The forces of supply and demand importantly contribute to the regional distribution of new firm formation. However, also the context in which demand and supply meet is important. This context is captured in institutions that are pertinent to new firm formation. Institutions have two sides. Firstly, formal institutions are made up by the body of rules and regulations. Secondly, there are informal institutions with an intangible side. These can be seen as the social context by which each member of society is influenced (North, 1994; Westlund and Bolton, 2003). For new firm formation these groups translate into policies and rules pertinent to setting up a business and the social capital that relates to new firm formation. If the local social capital is favourable to entrepreneurship it is also referred to as an entrepreneurial milieu or culture (see, for example, Wagner and Sternberg, 2002).

Rules and regulations have a double impact on new firm formation. Firstly, there is a rather straightforward impact through regulations that pertain to new firm formation. This is the red tape that needs to be overcome in order to start a firm. If there is much red tape to negotiate then new firm formation can be expected to be lower as start-up costs increase. Although relevant for policy this aspect is mostly nationally organized and less interesting in a discussion on the possible effects of globalization. Secondly, policy can have an indirect effect on start-ups. Henrekson (2005), for example, shows how the Swedish welfare system impedes on entrepreneurial efforts by taking away incentives for individuals to engage in entrepreneurship. Indirectly, cross-border policies can have a large impact on new firm formation. The EU with its policies aimed at establishing a large internal market for goods, capital, people and firms is arguably the best example. It shows that a larger market size is not only governed by technological progress, but that also institutional changes play a role. Finally, the stability and enforcement of rules strongly influences the business climate for entrepreneurs. If rules can change quickly over time and if property rights are not well defined or enforced, the risk associated with starting up a business increases. A stable set of rules can in itself have a positive influence. Globalization in this aspect could particularly benefit entrepreneurs in 'weak' states as international firms may pressure the government for stable rules. Also efforts of international cooperation in the EU and WTO may impact on this aspect.

The second aspect of institutions is the informal side or the entrepreneurial culture or climate $^{3}$. In empirical terms this side is probably best thought of as the residual that is left after explaining new firm formation by using supply and demand indicators. Although it is a vague notion,

\footnotetext{
${ }^{3}$ The distinction between formal and informal institutions is made in order to structure the argument. We recognize that both aspects are intimately connected.
} 
it can account for persistent difference in start-up levels between the USA and Europe (as shown by Bosma and Harding, 2007). It can also explain the persistence of the distribution of start-up rates as evidenced for Germany by Fritsch and Mueller (2007). Westlund and Bolton (2003) give a comprehensive theoretical account of the role of social capital in regional entrepreneurship. They make an important distinction between social capital that is favourable for entrepreneurship and social capital that is not. Given this distinction and the notion that social capital is a slowly changing path dependent process that is embodied in existing firm relationships, industrial composition and individual networks it can be assumed to be rather stable over time. This implies that the regional distribution of start-up rates will remain rather constant, even if there may be year-to-year differences in the level because of economic fluctuations (Andersson and Koster, 2007). Because of the path dependent nature in which social capital develops, it is not likely that globalization will rapidly change the entrepreneurial climate and consequent new firm formation. In fact, regions with a strong entrepreneurial culture can have an advantage over regions without such a culture in adopting the opportunities that arise from globalization. In the longer run, social capital may be influenced by globalization, particularly because the most entrepreneurial people are likely to go abroad and spread ideas on entrepreneurship. This can be seen in the case of migrant workers. These longer term effects however are rather unclear at the moment. It may be a self-reinforcing process in which areas with an entrepreneurial climate are most influenced by new entrepreneurial ideas, which reinforced the regional distribution of new firm formation currently in place.

\subsection{Regional dimensions}

Arguably, the most important effect of globalization on determinants of new firm formation is its impact on the number and characteristics of business opportunities. Particularly FDI can fulfil an important role in changing regional demand and the regional knowledge pool on which entrepreneurs can build their businesses. At the same time, some product markets increase in size, increasing potential demand in these markets. Particularly entrepreneurs from small home markets can benefit from this. It is, however, unclear whether increased market size will lead to a situation in which new firm formation will converge between regions. Market size is only one factor and even the accessibility of markets is still very unevenly spread across regions and industries. In addition, increased market size fosters increased competition, as one spatial market will be open to more producers. This may lead to structural changes in the regional pattern of producers, favouring those regions that have a competitive advantage for an industry. By the same token, the potential benefits of FDI seems also limited to those regions that are attractive for FDI. It shows that increased opportunities for entrepreneurship arising from globalizing forces may very well be limited to certain regions. Particularly regions that fulfil a hub function in the global economy and are receptive to the challenges set may benefit from this (see Sassen, 2006). 
In order to come to grips with the possible outcomes of globalizing forces it appears necessary to go beyond explaining regional start-up rates as such. The characteristics of new firm formation also warrant attention: how does the industry composition change, which links do entrepreneurs have to other companies, how global is the market for new firms? By addressing these questions the regional pattern of the impact of globalization on new firm formation may become much clearer than it is now.

3. The importance of new firm formation for regional economic growth: innovation, productivity and employment

The previous sections focussed on how forces of globalization may change conditions for new firm formation. We now turn to the impact of new firm formation on economic development at the regional level in the face of globalizing processes. Generally, new firm formation is considered crucial for long-term economic growth. In order to substantiate this claim, many empirical studies have been carried out (see, for recent reviews, Van Praag and Versloot, 2007 and Karlsson and Nyström, 2007). As a reference, Table 1 gives an overview of results found in 36 analyses that assess the relationship between entrepreneurship and various measures of economic development. It shows that in most cases entrepreneurship is indeed connected to economic growth.

Table 1: Found relationships between entrepreneurship and economic growth

\begin{tabular}{l|ll} 
& Positive & Insignificant or negative \\
\hline Productivity & 9 & 4 \\
Employment & 9 & 5 \\
Value added / BNP & 6 & 3 \\
\multicolumn{2}{l}{ Source: Karlsson and Nyström (2007), p.30 }
\end{tabular}

The current article does not aim at giving a comprehensive overview of the studies that have been made in the field. For that, the previously mentioned studies can be consulted. Rather, it tries to identify how and if globalization changes the link between new firm formation and economic growth. Although there is a large and diverse body of empirical research assessing the relationship between firm formation and economic growth, the theoretical ideas underpinning the studies are rather similar. There is little attention to the question whether the role of new firm formation may be different in distinct places or in distinct times. The remainder of the chapter tries to contribute to this question, taking globalization as an important process that may change the role of new firm formation in economic development. We address the role of new firm formation for innovation, productivity and employment growth. 


\subsection{New firm formation and economic development: innovation}

Entrepreneurship, expressed in new firm formation, has a theoretical connotation with innovation. If entrepreneurship is the creation of new combinations by individuals (Schumpeter, 1912), it has an inherent link to newness and progress. This works in several distinct ways. Not only does the entry of new firms push other, less efficient firms out, even the threat of entry may stimulate existing firms to produce more efficiently (Fritsch and Mueller, 2004). Apart from these effects, Fritsch and Mueller observe that new firms can play an important role in driving structural change by exploring new markets and that new firms can increase the number of product solutions through innovative entry. All these effects eventually contribute to increased innovation and economic rejuvenation. In the light of globalization, conceptualised as the enlargement of markets, the mechanism of these effects may change.

The enlargement of markets works towards a decreasing length of product life-cycles. Knowledge and information about products is disseminated more quickly, which reduces the period in which entrepreneurs can capitalise on a competitive advantage. Imitation and further development of products and services by competitors can be imminent. In addition, rapid dissemination of a product decreases the turnaround time of market information. In other words, the new product can be scrutinized by consumers quickly, which helps a dominant design to be installed quickly. In order to translate this effect of globalization into new firm formation, the distinction between exploitation and exploration is important (see, for example, Breschi and Lissoni, 2001). New firm formation based on exploitation is strongly rooted in existing practices and may even involve the direct imitation of an existing business idea (Schmitz, 1989). Exploration, in contrast, stresses the newness and trial-anderror function of new firm formation ${ }^{4}$. If indeed rapid dissemination of knowledge restrains the possibilities of ensuring a long term competitive advantage then entrepreneurship aimed at exploring new technologies and products is crucial for continuously establishing short term advantages. This would imply that innovative new firm formation is becoming more important for economic growth in a globalizing world.

Recently, studies have distinguished between types of entrepreneurship in order to capture the impact of innovative new firm formation. Both Mueller (2007) and Audretsch and Keilbach (2004) find for the German case that particularly high-tech and knowledge intensive start-up contribute to economic growth. Wong et al. (2005) corroborate this finding using GEM data at the country level: new firms based on the recognition of business opportunities govern economic growth. Based on these studies, it can be concluded that particularly new firm formation that is explorative in nature has a

\footnotetext{
${ }^{4}$ Liebenstein (1968) calls this N-type entrepreneurship.
} 
beneficial effect on economic development. Still, although innovative new firm formation may guide the direction of economic development, a quick exploitation of a short term competitive advantage may also be important, particularly for establishing a regional competitive advantage based on spatially confined knowledge advantages (Schmitz, 1989). Shorter product life cycles may prevent single firms to achieve scale efficiencies easily. New firm formation based on the exploitation of locally available knowledge may create a complex of smaller firms that together establish regional scale-benefits in production.

These ideas are again subject to the question to what extent the changes related to globalization (such as shorter product life-cycles) apply to distinct product categories and distinct regions. In addition, it can be argued that by the same token the notion of 'locally confined knowledge' may be less applicable, taking away incentives for clustering. Nevertheless, the argument shows that the interplay between innovation and replication can be an important feature of understanding the role of new firm formation in regional economic development and that globalization may indeed impact on this interplay.

\subsection{New firm formation and regional productivity growth}

The review of the empirical studies (Table 1) shows that most studies show a positive relationship between new firm formation and regional productivity growth. The direct effect of new firm formation on productivity seems limited, however. New firms have a competitive advantage in radical product innovations (Audretsch and Keilbach, 2004) rather than in productivity enhancing process innovations. This is in line with life-cycle theory which states that entry will become more difficult in later stages of the life-cycle, because scale in combination with high productivity, are then more important (Suarez and Utterback, 1995; Klepper, 1996). And indeed new firms have been shown to be built around product knowledge mostly (Koster, 2006). Still, a positive effect on productivity can be expected as new firm formation has indirect influences. Firstly, the threat of entry forces incumbent firms to increase productivity. Secondly, new firms play a role in the dissemination of knowledge which can be important in general productivity growth. This idea has been elaborated in the knowledge spillover theory of entrepreneurship (Acs et al, 2006).

The knowledge spillover theory of entrepreneurship contends that entrepreneurs act upon knowledge that is created within existing firms, for example as a result of R\&D activities. If incumbents do not commercialize this newly created knowledge, possibilities arise for entrepreneurs to base firms on this knowledge. In the process, knowledge is distributed to another organizational and spatial context. By starting new firms on the basis of existing knowledge, knowledge and routines are propagated to other places. There are two basic implications of this theory. First, in knowledge rich environments the start-up rate should be high (see Audretsch and Lehman, 2005). Second, start-ups disseminate knowledge and, as such, indirectly contribute to regional productivity (see Audretsch and 
Keilbach, 2004). The process of knowledge distribution through firm start-up can be affected by globalization through an increasing 'international' knowledge base. This process has two sides.

Firstly, domestic firms may become more international by increased foreign trade, alliances with foreign firms and international supplier relationships. As a result, the knowledge base of domestic firms may become more diverse and more international. Employees can use this knowledge for the benefit of their own firms, hereby disseminating global knowledge in a local context. This process has been summarised as 'Local buzz, global pipelines' (see, for example, Bathelt et al, 2005). It is interesting to note that internationalising firms are also the firms that are most innovative (see Suddle and Hessels, 2007 for a short overview). In that sense, international firms do not only partly drive globalization, they are also necessary for regions to tap into 'global knowledge pools'.

Secondly, as mentioned before, subsidiaries of foreign firms can increasingly serve as sources of local knowledge. This offers opportunities to tap into knowledge pools of other countries. Importantly, institutions and an entrepreneurial culture should be in place in order to reap the benefits from the access to new knowledge. Following the knowledge spillover theory of entrepreneurship, a lack of entrepreneurship can either be the result of too low an intensity of knowledge availability or of too few entrepreneurs that recognize and act upon entrepreneurial opportunities. In order to gain from FDI in a structural way, suitable institutions for recognizing and using imported knowledge appear crucial. Acs et al (2007a) indeed find support that Ireland has benefited from FDI more than Wales because of its receptive and entrepreneurial climate.

\subsection{New Firm Formation and Employment Growth}

Although theoretically new firm formation has an intrinsic link with increased productivity and economic growth in general terms, empirically new firm formation is often regarded in relationship with employment generation. A large body of empirical research on this issue has, however, not generated consensus. There are regional and temporal differences in the job generation capabilities of new firm formation ${ }^{5}$. In the USA, positive relationships are normally found (see, for example, Acs and Armington, 2004), but in Europe the evidence is less convincing. Particularly for the 1980s, studies have found negative impacts of new firm formation on regional employment change (Audretsch and Fritsch, 2002 for Germany and Van Stel and Storey, 2004 for the UK). In order to come to a more comprehensive idea of the impact on new firm formation on employment generation, Fritsch and Mueller (2004) take an explicit longitudinal approach. They describe a four stage model that is based on the idea that the effect of new firm formation has a temporal dimension. Initially, new firms have a direct employment generating effect. Even small firms offer employment to, at least, the founder of the firm. Assuming that part of the jobs previously occupied by the founders will be taken over by

\footnotetext{
${ }^{5}$ This can explain the results shown in Table 1.
} 
others, a direct increase of employment can be expected. After this initial stage, however, there may be negative effects on employment. Employment in incumbent firms may be threatened by increased competition. This phase mimics the phase of creative destruction, which involves the replacement of existing, less efficient firms. In addition, many new firms will not survive the first years of operation. Entry and exit rates are strongly correlated over time (see, for example, Karlsson and Nyström, 2002). These effects combined explain decreasing employment in this stage. After this stage, the effect becomes positive again because of the overall positive effect on the regional economy. This is in line with the Schumpeterian idea of development through entrepreneurship; the overall efficiency of a region may be increased, leading to employment growth. Finally, the effect of start-up in the base period fades away. Empirical evidence for this wave-shaped relationship has been found for the UK (Mueller et al, 2007), Germany (Fritsch and Mueller, 2004), Portugal (Baptista et al, 2007) and the Netherlands (Van Stel and Suddle, 2007). The evidence suggests that in order to assess the relationship between new firm formation and employment generation, a longitudinal setting is pivotal.

Apart from the role of new firm formation in reshaping the types of jobs that arise from new industries related to the global economy (Beyers, 2000), globalization can have an impact on the temporal dimension in job creation. If product life cycles become shorter on average, it can be expected that firm churning per time period may increase. In terms of the longitudinal model described in the above, it can be expected that the effects of new firm formation on employment generation may be much quicker. Overall, it could be expected that total employment in new firms may increase as it offers a flexible way of creating regional scale efficiencies that is necessary in an environment of shorter product life cycles. This remains an empirical question.

\subsection{The regional dimension}

In a globalizing economy, new firm formation remains important for regional economic growth. It can play an important role in the dissemination and application of (global) knowledge. New firm formation then plays a crucial role in the translation of new global knowledge into feasible businesses. In addition, outsourcing and the demand for flexible supplier relations may stimulate employment to concentrate in smaller firms. Finally, new firms may become important exporters, governing a country's position on the global market.

The relevant question again is to what extent these processes are in operation and which regions will benefit. How many new firms are actually touched by the forces of globalization and how does this influence their behaviour and consequent impact on economic development? This question is still open for further research. Acknowledging that internationalisation of trade and FDI have strong locational preferences for regions that are already prospering, it can be expected that a possible changing role of new firms will also become apparent in those areas. The results of globalization should then be interpreted as being path dependent with existing structures. This is consistent with the 
general framework of endogenous growth that links future growth to the strength of existing structures (Johansson and Karlsson, 2001). It questions the belief of globalization proponents that globalization will lead to convergence between regions.

Apart from possible 'real' changes, globalization induces a statistical overrepresentation of small and new firms in an economy. According to recent Dutch statistics (CBS, 2007) one in every three large firms (more than 100 employees) has been involved in a merger, of which many were international. This implies that the number of large firms declines as was indeed shown for the Netherlands. It, however, questions whether this should be interpreted as a sign that changing economic structures benefit new and small firms. The result does not preclude an alternative argument that globalization, as substantiated in international mergers, actually influences larger firms mostly.

\section{Conclusion}

This paper has provided an overview of how globalization can impact on new firm formation and its consequent influence on regional economic development. Although there is a large body of research on new firm formation, the economic context in which new firm formation takes place has received considerably less attention. Globalization, conceptualised as increasing market size as a result of institutional integration and decreasing travel and transportation costs, changes conditions for new firm formation and it may change the role of new firm formation in economic development. The main conclusion of this review is that there is very little concrete understanding about if and how globalization actually impacts on new firm formation. The conclusion of this paper is then probably best read as suggestions for research that addresses the issue of new firm formation in a globalizing economy. We distinguish two main avenues for research.

The first avenue is on the firm level and is concerned with the issue to what extent new firms are actually influenced by globalization. We know that most new firms start off small and that they are active in local markets. Only if successful they try to establish broader market shares. For a share of the new firms going abroad is not an option as their products are inherently local. Particularly personal services are bound in space. At the same time however, more new firms appear to enter the world market immediately (McDougall and Oviatt, 2000). The question how large this percentage is and if it is changing over time is still very much open though. Apart from internationalisation, globalization is also apparent in local supply of knowledge and local demand. FDI operations and immigration may change local knowledge pools and characteristics of local demand. Indeed in some areas FDI has played an important role in reshaping the regional business environment (Florida, 1996). However, it is still largely unknown whether these results can be generalized. Has new firm formation changed as a result of changing local demand and supply and if so, to what extent? Globalization plays a role in setting the conditions for new firm formation. Both demand and supply characteristics may change, but how new firm formation is influenced by this remains an open question. 
The second avenue of research is on the regional level and addresses the question if and how globalization will impact on the regional distribution of new firm formation. Again, the answer is unclear. On the one hand, increased accessibility of markets will benefit those regions that have a relatively small home market. The relative increase of the market size is greatest in these regions and this will create opportunities for entrepreneurs pushing formation rates upwards. On the other hand, it must be recognized that regional new firm formation is to a large degree path dependent (Fritsch and Mueller, 2007). Regions with an entrepreneurial climate may have an inherent advantage in seizing the opportunities that arise from globalization. In addition, links to global networks are still very unevenly spread. Although markets may open for all regions, some regions remain better connected than other regions. The possible changes in regional start-up rates and regional characteristics of new firm formation (industry breakdown for instance) in the face of globalization are then an empirical question. Which regions are influenced in the most profound way and how is new firm formation influenced? One preliminary answer points towards the importance of the adaptability and receptiveness of the labour market population.

A similar argument can be made concerning the relationship between new firm formation and economic development. Although there are arguments that point towards a new role of new firm formation for economic development, this could be dependent on where globalization actually has the most profound impact. Indeed, new firm formation may be important for realizing short term, flexible scale efficiencies in order to make use of smaller product life cycles, but this effect will be most visible in those regions that have the best connections to markets and knowledge. The spatial concentration of FDI and international trade is then an important topic of research in relationship to the question where knowledge for new firm formation is available and where it is not.

Although globalization may open up the world market for many regions, it is uncertain whether this will lead to a reshuffle of economic development, for example governed by developments in new firm formation. Competition is fierce and it is a question of which regions are ready to take the opportunities that globalization offers. 


\section{References}

Acs Z.J. and C. Armington (2004). Employment growth and entrepreneurial activity in cities. Regional Studies 38 (8), pp. 911-927.

Acs Z.J., D. Audretsch, P. Braunerhjelm \& B. Carlsson (2006). The knowledge spillover theory of entrepreneurship. CESIS, Electronic Working Paper Series.

Acs Z.J., C. O'Gorman, L. Szerb and S. Terjesen (2007a). Could the Irish miracle be repeated in Hungary. Small business economics 28 (2), pp.123-142.

Acs Z.J. and D.J. Storey (2004). Introduction: entrepreneurship and economic development. Regional Studies 38 (8), pp. 871-877.

Acs Z.J., D.J. Brooksbank, C. O'Gorman, D.G. Pickernell and S. Terjesen (2007b). The knowledge spillover theory of entrepreneurship and foreign direct investment. Jena Economic Research Papers 07-059. Max Planck Institute of Economics: Jena.

Andersson M. (2007). Disentangling trade flows: Firms, geography and technology. Dissertation, Jönköping International Business School.

Andersson M. and S. Koster (2007). Persistence in start-up rates: evidence from Sweden. Mimeo

Audretsch D.B. and M. Fritsch (2002). Growth regimes over time and space. Regional Studies 36 (2), pp. 113124.

Audretsch D. and M. Keilbach (2004). Entrepreneurship and regional growth: an evolutionary interpretation. Journal of evolutionary economics 14 (5), pp. 605-616.

Audretsch D.B. and E.E. Lehman (2005). Does the knowledge spillover theory of entrepreneurship hold for regions? Research Policy 34 (8), pp. 1191-1202.

Baptista R., V. Escária and P. Madruga (2007). Entrepreneurship, regional development and job creation: the case of Portugal. Small Business Economics 28 (4), pp.

Barrell R. and N. Pain (1999). Domestic institutions, agglomerations and foreign direct investment in Europe. European Economic Review 43 (4-6), pp. 925-934.

Bathelt H., A. Malmberg and P. Maskell (2005). Clusters and knowledge: local buzz, global pipelines and the process of knowledge creation. Progress in human geography 28 (1), pp.31-56.

Baumol W. (1968). Entrepreneurship in economic theory. The American economic review 58 (2), pp. 64-71.

Baumol W. (1990). Entrepreneurship: Productive, unproductive and destructive. The journal of political economy 98 (5), pp. 893-921.

Baycan-Levent T and P. Nijkmap (2005). Determinants of migrant entrepreneurship in Europe. Conference paper ERSA-conference 2005, Amsterdam.

Beyers W.B. (2002). Services and the new economy. Journal of economic geography 2 (1), pp. 1-29.

Birch D.L. (1979). The job generation process. MIT press, Cambridge

Breschi S. and F. Lissoni (2001). Knowledge spillovers and local innovation systems: a critical survey. Industrial and corporate change 10 (4), pp. 975- 1005.

Bosma N. and R. Harding (2007). Global entrepreneurship monitor. 2006 Summary results. Babson College and London Business School.

Centraal Bureau voor de Statistiek (Dutch Statistics) (2007). Statistical yearbook 2007. CBS: Voorburg / Heerlen.

Chell E. (1986). The entrepreneurial personality: a review and some theoretical developments. In: Curran J., J. Stanworth \& D. Watkins. The survival of the small firm: the economics of survival and entrepreneurship. Cowan Publishing, Aldershot

Christaller W. (1933). Die zentralen Orte in Süddeutschland. Gustav Fischer: Jena.

Clercq D. de, J. Hessels and A. van Stel (2007). Knowledge spillovers and entrepreneurs' export orientation. ERIM Report series ERS-2007-038-ORG, Rotterdam.

Dicken P. (2007). Global shift. Mapping the changing contours of the world economy. $5^{\text {th }}$ edition, Sage: London. 
Florida R. (1996). Regional creative destruction: production organization, globalization, and the economic transformation of the Midwest. Economic Geography 72 (3), pp. 314-344.

Friedman T. (2005). The world is flat. A brief history of the $21^{\text {st }}$ century. Farrar, Straus and Giroux: New York.

Fritsch M. and P. Mueller (2004). Effects of business formation on regional development over time. Regional Studies 38 (8), pp. 961-975.

Fritsch M. and P. Mueller (2007). The persistence of regional new business formation-activity over time assessing the potential of policy promotion programs. Journal of Evolutionary Economics 17 (3), pp.299-315.

Garvin D.A. (1983). Spin-offs and the new firm formation process. California Management Review 25 (2), pp. $3-20$.

Görg H. and E. Strobl (2002). Multinational companies and indigenous development: and empirical analysis. European Economic review 46 (7), pp. 1305-1322.

Henrekson M. (2005). Entrepreneurship: A weak link in the welfare state. Industrial and corporate change 14 (3), pp. 437-467.

Hofstede G. (2001). Culture's consequences: comparing values, behaviors, institutions and organizations across nations. Sage: Thousand Oaks.

Johansson B. and C. Karlsson (2001). Geographic transaction costs and specialisation opportunities of small and medium-sized regions: scale economies and market extension. In: In: Johansson B., C. Karlsson and R. Stough. Theories of endogenous regional growth: lessons for regional policies. Springer: Berlin

Karlsson C. (2001). Endogenous regional growth and policies. In: Johansson B., C. Karlsson and R. Stough. Theories of endogenous regional growth: lessons for regional policies. Springer: Berlin

Karlsson C. and K. Nyström (2007). Nyföretagande, näringslivsdynamik och tillväxt i den nya världsekonomi. Mimeo

Klepper S.J. (1996). Entry, exit, growth and innovation over the product life-cycle. The American economic review 86 (3), pp. 562-583.

Klepper S.J. (2001). Employee startups in high-tech industries. Industrial and Corporate Change 10 (3), pp. 639-674.

Knight F.H. (1921). Risk, uncertainty and profit. Boston: Hart, Schaffner \& Marx, Houghton Mifflin Company

Koster (2006). Whose Child. How existing firms foster new firm formation: Individual start-ups, spin-outs and spin-offs. Dissertation, Groningen university

Leibenstein H. (1968). Entrepreneurship and development. The American economic review 58 (2), pp.72-83.

Levie J. (2007). Immigration, in-migration, ethnicity and entrepreneurship in the United Kingdom. Small Business Economics 28 (2), pp. 143-169.

McDougall P.P. and B.M. Oviatt (2000). International entrepreneurship: The intersection of two paths. Academy of Management Journal 43 (5), pp. 902-906.

Mueller P., A. van Stel and D.J. Storey (2007). The effects of new firm formation on regional development over time: the case of Great Britain. Small Business Economics 28 (4), pp. 362-.

Mueller P. (2007). Exploiting entrepreneurial opportunities: the impact of entrepreneurship on growth. Small Business Economics 28 (4), pp.

North P. (1994). Economic performance through time. American economic review 84 (3), pp. 359-368.

Praag M. van and P.H. Versloot (2007). What is the value of entrepreneurship? A review of recent research. Jena economic research papers 07-061. Max Planck Institute for Economics: Jena

Reynolds P.D., B. Miller and W.R. Maki (1995). Explaining regional variation in business births and deaths: U.S. 1976-1988. Small business economics 7 (5), p.389-407.

Reynolds P.D. (1997). New and small firms in expanding markets. Small business economics 9 (1), pp. 79-84.

Sassen S. (2006). Cities in a world economy. Pine Forge Press: Thousand Oaks, updated $3^{\text {rd }}$ edition.

Schmitz jr. J.A. (1989). Imitation, entrepreneurship, and long-rub growth. Journal of political economy 97 (3), pp.721-739. 
Schumpeter J.A. (1912) Theorie der wirtschaftlichen Entwicklung: eine Untersuchung über Unternehmengewinn, Kapital, Kredit, Zins und Konjunkturzyklus. Duncker \& Humblot: München and Leibzig.

Shane S.A. (2000). Prior knowledge and the discovery of entrepreneurial opportunities. Organization Science 11 (4), pp. 448-469.

Shane S.A. (2005). A general theory of entrepreneurship. The individual-opportunity nexus. Edward Elgar, Cheltenham, Northampton

Stam E. (2003). Why butterflies don't leave. Locational evolution of evolving enterprises. PhD-thesis. Utrecht: University of Utrecht.

Stel A.J. van and D.J. Storey (2004). The link between firm birth and job creation: Is there a upas tree effect? Regional Studies 38(8), pp. 893-909.

Stel A. van, K. Suddle (2007). The impact of new firm formation on regional development in the Netherlands. Small Business Economics 28 (4), pp. XX-Xx.

Suarez F.F. and J.M. Utterback (1995). Dominant design and the survival of firms. Strategic management journal 16 (6), pp. 415-430.

Suddle K. and S.J.A. Hessels (2007). Global entrepreneurship monitor. Nederland. Zoetermeer: Economisch Instituut voor het Midden- en kleinbedrijf.

Townroe P.M. (1975). Branch plants and regional development. Town Planning Review 46 (1), pp. 47-62.

Verheul I., S. Wennekers, D. Audretsch and R. Thurik (2001). An eclectic theory of entrepreneurship. Tinbergen Discussion Paper 2001-030/3. Rotterdam: Tinbergen Institute.

Wagner J. and R. Sternberg (2002). The role of the regional milieu for the decision to start a new firm: empirical evidence for Germany. IZA Discussion Paper Series 494. IZA: Bonn.

Westhead P., M. Wright and D. Ucbasaran (2001). The internationalization of new and small firms: a resourcebased view. Journal of business venturing 16 (4), pp.333-358.

Westlund H. and R. Bolton (2003). Local social capital and entrepreneurship. Small Business Economics 21 (2), pp.77-113.

Wong P.K., Y.P. Ho and E. Autio (2005). Entrepreneurship, innovation and economic growth: Evidence from GEM data. Small Business Economics 24 (3), pp. 335-350. 